\title{
Unplanned Subject Element Description
}

National Cancer Institute

\section{Source}

National Cancer Institute. Unplanned Subject Element Description. NCI Thesaurus. Code C83412.

A written or verbal account of a study subject element that was unexpected. 